\title{
Strategies for ensuring that regenerative cardiomyocytes function properly and in cooperation with the host myocardium
}

\author{
Fumiyuki Hattori $^{1,2,3}$ and Keiichi Fukuda ${ }^{1,3}$ \\ ${ }^{1}$ Division of Cardiology \\ Department of Medicine \\ Keio University School of Medicine \\ Tokyo, Japan \\ ${ }^{2}$ Asubio Pharma Co., Ltd., \\ Osaka, Japan \\ ${ }^{3}$ Corresponding authors: E-mail, hattori@ sc.itc.keio.ac.jp (F.H.); \\ E-mail, kfukuda@sc.itc.keio.ac.jp (K.F.) \\ DOI 10.3858/emm.2010.42.3.022
}

Accepted 25 January 2010

Available Online 11 February 2010

Abbreviations: EGFP, enhanced green fluorescent protein; EPC, endothelial progenitor cell; ES cells, embryonic stem cells; iPS cells, induced pluripotent stem cells

\begin{abstract}
In developed countries, in which people have nutrient-rich diets, convenient environments, and access to numerous medications, the disease paradigm has changed. Nowadays, heart failure is one of the major causes of death. In spite of this, the therapeutic efficacies of medications are generally unsatisfactory. Although whole heart transplantation is ideal for younger patients with heart failure, many patients are deemed to be unsuitable for this type of surgery due to complications and/or age. The need for therapeutic alternatives to heart transplantation is great. Regenerative therapy is a strong option. For this purpose, several cell sources have been investigated, including intrinsic adult stem or progenitor cells and extrinsic pluripotent stem cells. Most intrinsic stem cells seem to contribute to a regenerative environment via paracrine factors and/or angiogenesis, whereas extrinsic pluripotent stem cells are unlimited sources of cardiomyocytes. In this review, we summarize the various strategies for using regenerative cardiomyocytes including our recent progressions: non-genetic approaches for the purification of cardiomyocytes and efficient transplantation. We expect that use of intrinsic and extrinsic stem cells in combination will enhance therapeutic effectiveness.
\end{abstract}

Keywords: embryonic stem cells; guided tissue regeneration; heart; induced pluripotent stem cells; myocytes, cardiac; transplants

\section{Introduction}

The heart is designed as a blood pump that works from the earliest organogenetic stage until death. Cardiomyocytes lose the ability to undergo cytokinesis soon after birth, which means that instead they hypertrophy in line with the increased demand for blood supply; which may be an evolutionary strategy to avoid tumorigenesis and achieve long-term stable and high-power pumping functions. However, once a certain number of cardiomyocytes is lost, the functional loss is compensated by pathological hypertrophic remodeling of the remaining cardiomyocytes, which have limited capacity. The excessive remodeling and overload of cardiomyocytes causes their sequential death and an irreversible circle of degeneration.

Although whole heart transplantation is the optimal treatment for a severely failing heart, the numbers of donor hearts are limited. Furthermore, many patients who suffer heart failure are excluded from transplantation therapy due to complications and/or age. Therefore, revolutionary therapeutic alternatives to heart transplantation that can be applied to patients with general congestive heart failure are urgently needed. Heart regenerative therapy is a strong candidate for this type of therapy.

For the proper regeneration of heart functions, it is necessary to have a clear understanding of the nature of this organ. The heart is a complex organ that consists of various types of cells, including cardiomyocytes and non-cardiomyocytes. Cardiomyocytes can be categorized as atrial, ventricular, pacemaking, and purkinje. Furthermore, ventricular cardiomyocytes are functionary sub-divided into $\mathrm{M}$-cell, sub-endocardial, and sub-epicardial cardiomyocytes. Non-cardiomyocytes include fibroblasts, endocardial and epicardial cells, vascular endothelial and smooth muscle cells, sympathetic and parasympathetic cells, valvular and chordal cells, and cardiac-resident immune cells. These cell types work co-operatively to create the physiologic heart. Therefore, to ensure that regenerative cardiomyocytes function properly, provision of the appropriate regenerative environment is critical. 


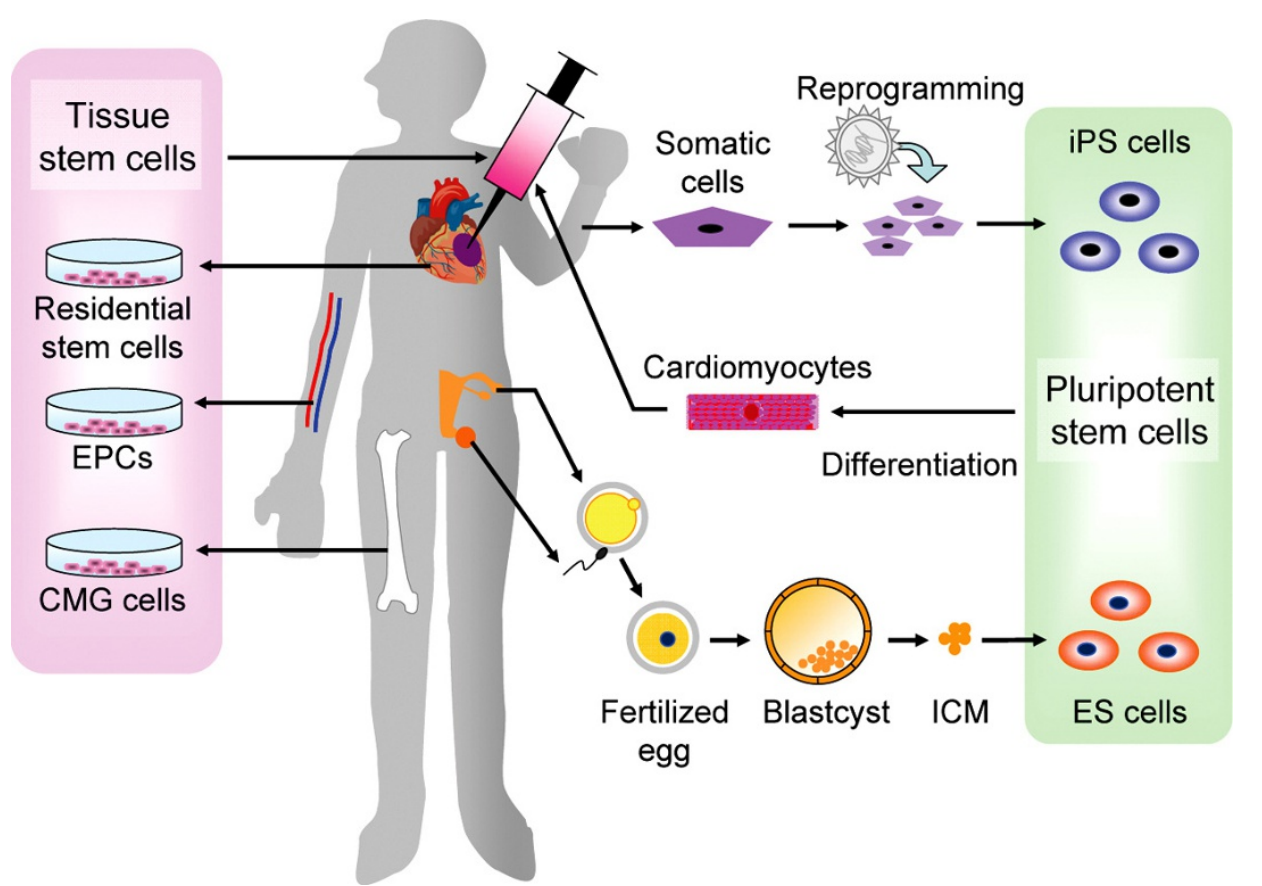

Figure 1. Sources of cells for regenerative therapies.
There are many candidate cell sources for heart regenerative therapies, such as cardiac-resident, bone marrow, and peripheral blood-derived stem cells. However, no adult stem cell-based strategy has achieved the production of sufficient numbers of cardiomyocytes to enable functional recovery of the failing heart. It is clear that the primary role of some adult stem cells is the creation of the regenerative environment rather than regeneration of cardiomyocytes. Therefore, cardiomyocyte administration/substitution from outside sources, e.g., human embryonic and induced pluripotent stem cells, appears to be promising (Figure 1).

In the present report, we introduce strategies for the preparation and delivery into the host myocardium of stem cells. The ultimate goal is to ensure that regenerative cardiomyocytes work properly and co-operatively with the host myocardium. Although different strategies are being tested, we believe that these studies will generate safe and effective therapies in the future.

\section{Selection of cell sources}

\section{Tissue stem cells}

In 1999, we demonstrated that bone marrow mesenchymal stem cells, which we term cardiomyogenesis cells, transdifferentiated into cardiomyocytes after treatment with 5-azacytidine (Makino et al., 1999). This finding and previously obtained information on heart-derived cardiomyocytes
(Soonpaa et al., 1994) ushered in the concept of "heart regeneration therapies with own cardiogenic stem cells". Furthermore, we demonstrated the transplantation of cardiomyogenesis cells into the heart and observed that the integrated cardiomyogenesis cells had features of the adult myocardium (Hattan et al., 2005). However, the cardiomyogenesis-based therapy has two major drawbacks: (1) the need to use the teratogenic reagent 5-azacytidine; and (2) low efficiency in terms of the establishment of cardiogenic cell lines from primary cultures of bone marrow adhesive cells. Despite intensive investigations, we have not yet overcome these obstacles.

5-Azacytidine is known to be an inhibitor of DNA methyltransferase (Kiefer, 2007). Recent publications have revealed the relationships between epigenetic modifications and the developmental specification of cell fates (Kiefer, 2007). In this context, we believe that cardiomyogenesis cells represent dedifferentiated cardiogenic stem cells. Other stem cells that have been identified for cardiomyocyte generation include endothelial progenitor cells (EPCs) (Asahara, 2007), c-kit (Beltrami et al., 2003), sca-1 (Oh et al., 2004), isl-1 (Laugwitz et al., 2005), and neural crest stem cells (Tomita et al., 2005). Asahara's group first reported the existence in the peripheral blood of multipotent stem cells, which are recruited into injured tissues and contribute to healing. They showed that EPCs not only differentiate into vessel endothelial and smooth muscle cells, but also cardiomyocytes, 
albeit with very low efficiency. The c-kit-positive cells were identified as residential stem cells by Anversa's group (Beltrami et al., 2003); these cells can repopulate cardiomyocytes under both normal and pathologic conditions. They reported that transplantation of collected and concentrated c-kit-positive cells dramatically improved cardiac function and inhibited remodeling. Moreover, they developed a method for expanding c-kit-positive stem cells in vitro (Beltrami et al., 2003). The cardiogenic potential of sca-1-positive stem cells was first reported by $\mathrm{Oh}$ and colleagues (Oh et al., 2004). These authors showed that sca-1-positive cells have high telomerase activity and can be differentiated into cardiomyocytes in vitro through treatment with 5-azacytidine. They also indicated that sca-1-positive cells have the potential to promote regenerative healing in vivo through both fusion and non-fusion cardiogenic transdifferentiation mechanisms.

Isl1 cells were discovered as cardiac-lineage progenitor cells by Chien's group (Laugwitz et al., 2005). They reported the expression of transcription factor Isl1 in secondary cardiogenic cells at the cardiac crescent stage. From lineage-tracing studies, Isl1-positive cells have been found to contribute to atrial and right ventricular construction. Few Isl1-positive cells are observed in the neonatal atrial right ventricular, and they are absent from the adult heart. Isl1-positive cells can be isolated from murine embryonic stem cells, and they can be expanded and differentiated into vascular endothelium, vascular smooth muscle, and cardiomyocytes. Tomita et al. (2005) have shown that mammalian neural crest-derived cells have the potential to differentiate into cardiomyocytes, and they regard neural crest stem cells as new residential multipotential progenitor cells.

\section{Pluripotent stem cells}

Embryonic stem cells: Embryonic stem (ES) cells can be produced from the blastocyst inner cell mass. Therefore, the production of human ES cells from embryos raises ethical concerns. This is the major drawback to the use of human ES cells for research and therapeutics. Differences in the differentiation abilities of several ES cell lines have been reported (Moore et al., 2008). Some researchers have attributed this to differences in epigenetic modifications or the accumulation of certain mutations. Since the differentiation efficiencies are generally low, the enhancement of differentiation efficiency has been studied extensively. ES cells have the ability to produce teratomas upon transplantation into immunodeficient animals
(Prokhorova et al., 2008). Therefore, in applications involving cells differentiated from ES cells, undifferentiated ES cells and unwanted cells must be excluded. Some studies have reported the susceptibility of human ES cells to become 'cancer ES cells' through the accumulation of mutations and genomic rearrangements (Harrison et al., 2007). Although ES cells can theoretically proliferate indefinitely, many researchers believe that ES cells that have undergone more than 30 passages should not be used even for research purposes. The methodologies used for culturing and expanding ES cells should be stringently verified with respect to genomic and epigenetic stability. For ES cells used in therapies, an animal cell-free culture system should be used. Recently, improved systems have been reported, and some of these are already commercially available.

Induced pluripotent stem (iPS) cells: Recently, Takahashi et al. revealed that induced pluripotent stem (iPS) cells could be generated not only in mice (Takahashi and Yamanaka, 2006), but also in humans (Takahashi et al., 2007); this may allow us to obtain individual ES-like cells. In our hands, the established murine iPS and ES cells and human iPS and ES cells are similar in terms of cell morphology, stem cell marker expression, and teratoma formations. However, cardiogenic differentiation properties tend to be lower than ES cells. The greatest advantage of iPS cells for stem cell researchers is that they do not have the ethical issues of ES cells, as they are derived from non-embryonic sources, although there are many unrevealed cocerns in iPS cells.

\section{Mass production of ES cell-derived cardiomyocytes}

For the eventual application of ES/iPS cell-derived cardiomyocytes, there are two major prerequisites: 1) improvement of the efficiency of differentiation into cardiomyocytes; and 2) efficient mass production of the differentiated cells. Many attempts have been made to improve cardiogenic differentiation efficiencies (Wobus et al., 1997; Sauer et al., 2000; Pandur et al., 2002; Paquin et al., 2002; Choi et al., 2004; Kanno et al., 2004; Passier et al., 2005; Stary et al., 2005; Yuasa et al., 2005; Zhu and Lou 2005; E et al., 2006; Hosseinkhani et al., 2007a, 2007b; Roggia et al., 2007; Singh et al., 2007). However, inter-species, inter-strain, inter-laboratory, and even intra-laboratory variabilities have been problematic, and differentiation efficiencies $>30 \%$ (cell-based counting) have not been achieved 


\section{ES and iPS cells}

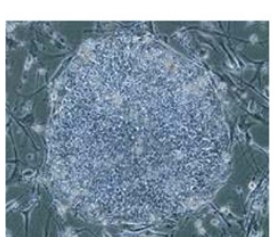

differentiation
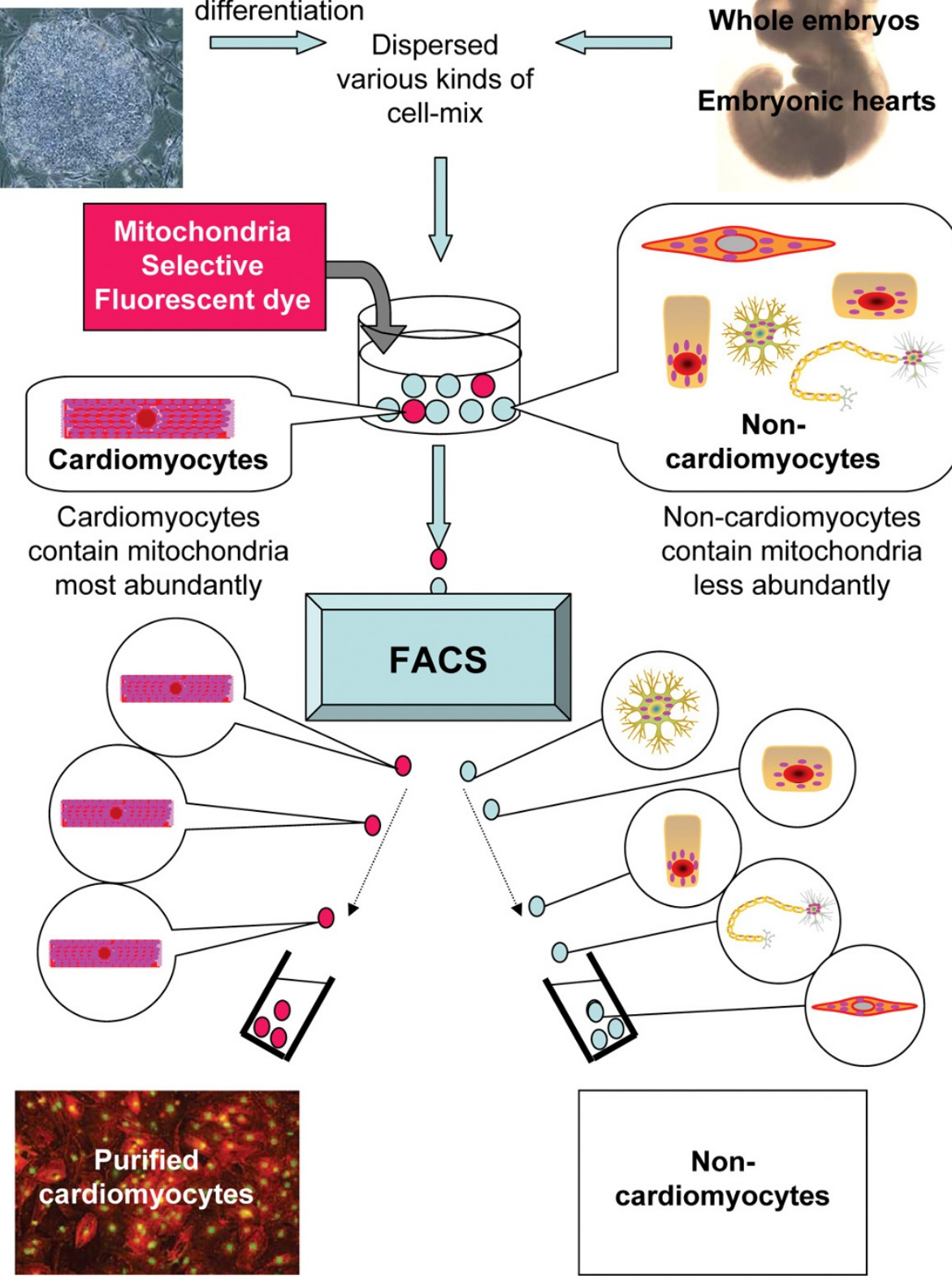

Figure 2. Scheme for the purification of cardiomyocytes from cell mixtures using a nongenetic method.

without enrichment. This may reflect susceptibilities to epigenetic fluctuations during maintaining cultivations and the difficulties experienced in controlling and unifying the individual states of differentiating cells due to cell-cell interactions. The scaling up of cultures is not easy. For this purpose, several groups have used the combination of micro-carriers and spinner flasks (Bauwens et al., 2005; Schroeder et al., 2005; Rourou et al., 2007). In the next step of large-scale culturing, some groups have applied gene modification-based enrichment methods for murine embryonic stem cells, and obtained high numbers of enriched cardiomyocytes (Bauwens et al., 2005).

\section{Enrichment and purification of cardiomyocytes}

Purification of ES-CM cells was first reported by Klug and colleagues in 1996 (Klug et al., 1996), who established murine ES cell lines by permanent gene transfection of the aminoglycoside phosphotransferase (neo) gene driven by the $\beta$-myosin heavy chain promoter, and obtained highly enriched ES-CM cells ( $>99 \%$ pure). Thereafter, several 


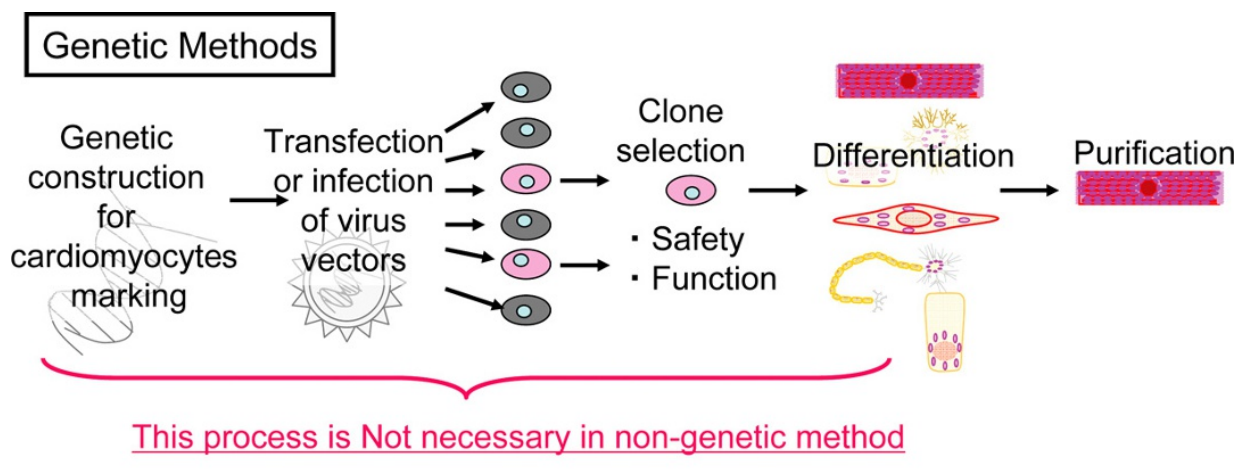

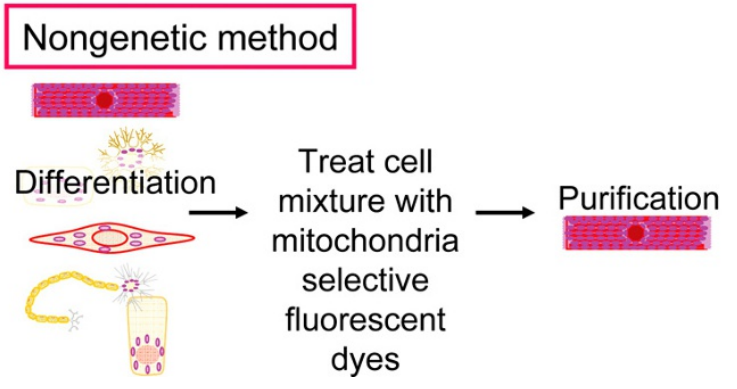

studies tested various combinations of cardiomyocyte-specific promoters and reporters to obtain pure ES-CM cell populations, including the stable transfection of the enhanced green fluorescent protein (EGFP)-tagged myosin light chain-2v promoter (Muller et al., 2000), EGFP knock-in to the Nkx2.5 locus (Hidaka et al., 2003), stable transfection of the $\mathrm{Na}^{+} / \mathrm{Ca}^{2+}$ exchanger promoter (Fijnvandraat et al., 2003), and stable transfection of the EGFP-tagged atrial natriuretic peptide promoter (Gassanov et al., 2004). Anderson et al. (2007) demonstrated the enrichment of human ES-CM cells ( $>93 \%$ ) utilizing genetic modifications. Recently, we developed a widely applicable enrichment method that gives the highest level of cell purity (Hattori et al., 2010). Initially, we applied the fluorescent mitochondrion-selective indicator MitoTracker Red to neonatal rat heart-derived cells, which contained cardiomyocytes and non-cardiomyocytes, and found that the dye selectively accumulated within the cardiomyocytes. This observation led us to hypothesize that mitochondrial dyes might be useful in cardiomyocyte purification (Figure 2). We validated this hypothesis using embryonic heart and whole embryo-derived cells. Next, we successfully purified mouse, marmoset (monkey), and human ES cells and mouse and human iPS cell-derived cardiomyocytes from their respective embryoid bodies. The purities of these cell populations were verified by sequential immunofluorescence FACS analysis. The expression of several cardiomyocyte marker genes was detected, whereas that of non-cardiomyocyte marker genes was not detected by PCR amplification of reverse-transcribed mRNAs extracted from the purified human ES cell-derived cardiomyocytes. Finally, we transplanted $1.9 \times 10^{5}$ purified mouse ES cell-derived cardiomyocytes into immunodeficient mouse testes, and confirmed the absence of teratoma formation (Hattori et al., 2010). Our method for cardiomyocyte isolation has two advantages. First, it does not require genetic modification of the cells. Genetic modifications using non-viral or viral systems have several disadvantages, i.e., extrinsic genes may be silenced, the number of integration events in a single cell is difficult to control, targeted integration is not straightforward, and line selection and the verification of proper expression of extrinsic genes are time-consuming. Furthermore, genetic modification entails certain risks, such as tumor formation. Second, our method is likely to be widely applicable. We demonstrate here that it may be used to purify ESC-derived cardiomyocytes from four species, including humans, and that it is also applicable to murine and human iPSCs. An abundance of cellular mitochondria is likely to be a common characteristic of cardiomyocytes, irrespective of species. In contrast, most genetic modifications require species-specific constructs. The ESC-derived cardiomyocytes purified using our method did not induce teratoma formation in either the heart or testes (Figure 3). Although for clinical safety, further studies using large animal 
models with much higher numbers of ESC-derived cardiomyocytes will be required, we believe that our purification method has significant advantages over existing methods in terms of eventual clinical applications.

\section{Transplantation strategies}

\section{Direct injection}

Direct injection of heart-derived cardiomyocytes: Soonpaa et al. first reported intramyocardial injection of embryonic cardiomyocytes and nascent intercalated disk formation (Soonpaa et al., 1994). Regarding injection into an infracted heart Leor et al. reported the injection of cultured fragments of human fetal ventricles or rat fetal ventricles into the scar of a 7-24-day-old reperfused myocardial infarction in a rat (Leor et al., 2000). Scorsin et al., reported injecting cultured neonatal rat cardiomyocytes into the border zone of a myocardial infarction created permanent coronary occlusion (Scorsin et al., 1996). The viability of the graft was demonstrated up to $48 \mathrm{~h}$ post-transplantation. Reinecke et al. demonstrated the transplantation of fetal, neonatal, and adult cardiomyocytes into normal and cryoinjured hearts (Reinecke et al., 1999). They observed that neonatal rat cardiomyocytes hypertrophied to close to the size of adult cardiomyocytes by 8 weeks. Watanabe et al., demonstrated the transplantation study using porcine myocardial infarction model (Watanabe et al., 1998). They transplanted fetal and neonatal pig cardiomyocytes into the hearts with 4 to 5 -week-old infarctions, and failed to show the presence of grafted fetal or neonatal pig cardiomyocytes. The discrepancies among these two reports are likely due to differences in the species studied and/or how recently the injuries occurred.

Direct injection of ES cell-derived cardiomyocytes: Klug et al. first reported the transplantation of murine ES cell-derived cardiomyocytes into the heart of a mouse (Klug et al., 1996). They highly enriched cardiomyocytes using genetic engineering (>99\%) and transplanted these cells, although the transplanted cardiomyocyte number was very few $\left(1 \times 10^{4}\right)$. They extracted DNA from the heart which had been received the transplantation seven weeks before, and amplified the graft cell-specific DNA sequence by PCR and detected that by Southern blotting. The successful engraftment using highly enriched cardiomyocytes (>99\%) have not been reported after Klug's reports, although many studies using various genetic techniques for cardiomyocyte marking were reported.
Kollosov et al. reported that the co-transplantation of highly enriched cardiomyocytes $\left(1 \times 10^{5}\right.$ cells $)$ with fibroblasts resulted in good survival of the donor cardiomyocytes (Kolossov et al., 2006). With regard to human ES cells, Kehat et al. reported that human ES cell-derived cardiomyocytes could normalize complete electrical heart block through the injection of beating embryoid bodies (Kehat et al., 2004). Laake et al. achieved long-term engraftment of human ES cell-derived cardiomyocytes in the infracted hearts of immunodeficient mice, and showed that a transient improvement was effected by engrafted cardiomyocytes, as compared with engrafted non-cardiomyocytes. However, they reported that the improvement conferred by cardiomyocytes dropped to the same level as that produced by the engraftment by non-cardiomyocytes (van Laake et al., 2007). Laflamme et al. transplanted cardiomyocyte-containing embryoid bodies into rat myocardium (Laflamme et al., 2005), reported the introduction of enriched human ES cell-derived cardiomyocytes $\left(10 \times 10^{6}\right.$ cells $)$ into infracted myocardium, and confirmed histologically the survival of these cells (Laflamme et al., 2005). Van Laake et al. (van Laake et al., 2007) histologically analyzed engrafted human ES cell-derived cardiomyocytes and speculated that the reason why the cardiomyocytes did not confer long-term improvement was that the engrafted cardiomyocytes produced human extracellular matrix, which hampered their electrical and functional connections and hindered co-operation with the host cardiomyocytes. They also stated that in the current strategies, the cardiomyocytes derived from ES cells could not functionally integrate with the host cardiomyocytes.

Survival of transplanted cardiomyocytes: The numbers of cells remaining in the myocardium after transplantation were investigated by Muller-Ehmsen et al. (Muller-Ehmsen et al., 2002). They reported that almost $80 \%$ of the injected cells were lost between 1 day and 4 weeks post-injection, irrespective of the number of injected cells, whereas in the short period of time $(1 \mathrm{~h})$ after transplantation, there was a negative relationship between the number of lost cells and the number of injected cells. Dow et al. injected neonatal rat cardiac cells $\left(5 \times 10^{6}\right)$ directly into the free wall of the left ventricle at either 15 min post-reperfusion or 75 min after permanent occlusion (Dow et al., 2005). Histological analysis of the transplanted cells revealed that the cardiac blood vessels contained cardiomyocytes. PCR analysis revealed that $100 \%$ of the animals ( 5 out of 5 ) in both groups had cells in their hearts and lungs, $40 \%$ of the reperfusion 


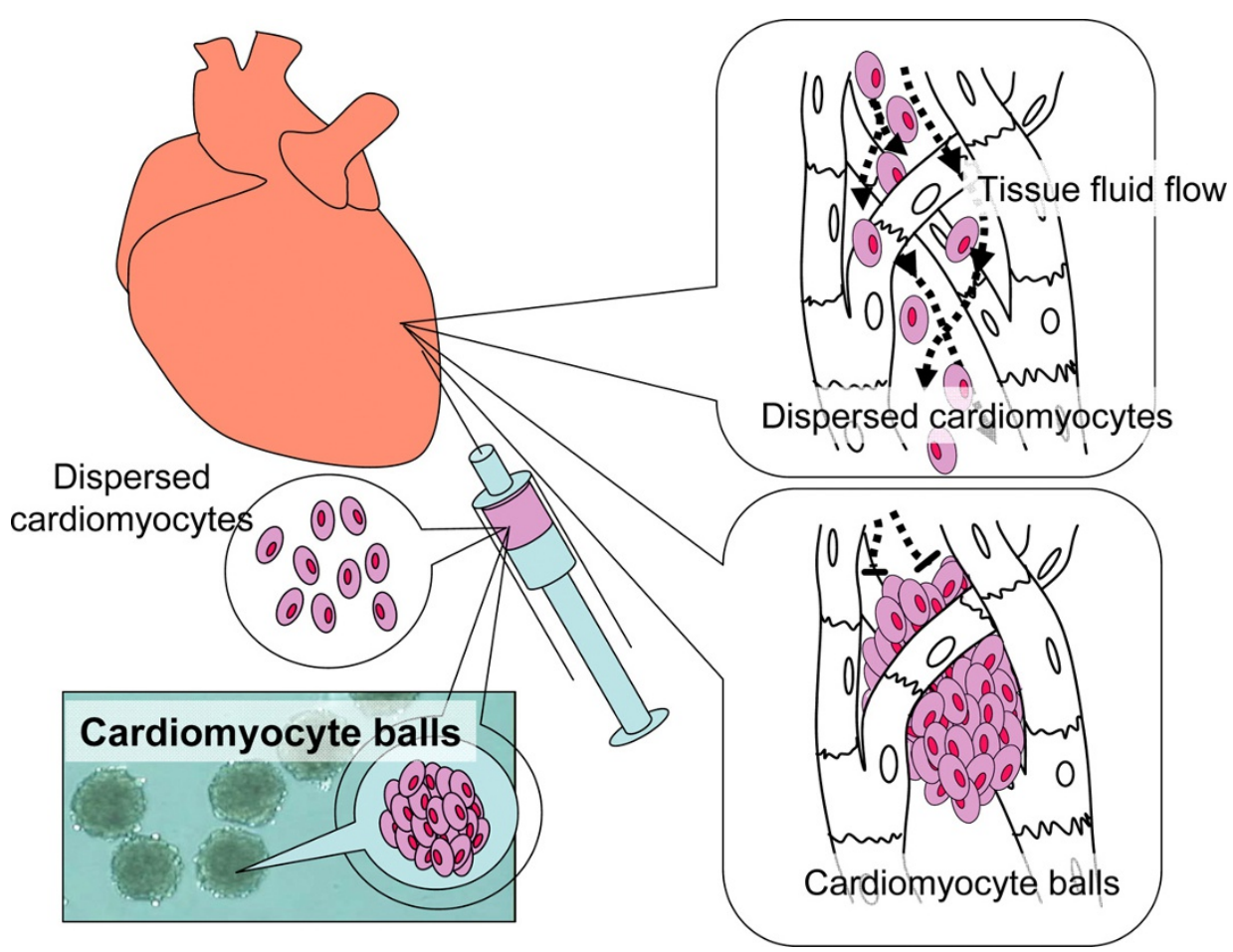

Figure 4. Schematic of the re-aggregation method for the efficient transplantation of FACS-purified cardiomyocytes. group and $60 \%$ of the permanent occlusion group demonstrated cells in the liver and kidneys, and $40 \%$ of the permanent occlusion group had cells in the spleen. These results suggest that suspended cardiomyocytes are washed out into the circulation and spread throughout the body. Kollosov et al., reported that genetically highly enriched mouse ES cell-derived cardiomyocytes did not survive in the heart (Kolossov et al., 2006). Co-transplantation with fibroblasts synergistically enhanced the survival of these cells in the host myocardium. When we transplanted highly purified ES cell-derived cardiomyocytes and mouse embryonic fibroblasts into mouse hearts, histologic analysis showed that $<1 \%$ of the cardiomyocytes and $50 \%$ of the fibroblasts remained in the myocardium after $24 \mathrm{~h}$ (Hattori et al., 2010). These results indicate that differences in adhesive abilities may be crucial. Furthermore, to investigate the possibility of rapid washing out via the coronary circulation, we injected purified and labeled cardiomyocytes into an ex vivo perfused heart. The drainage fluids from the coronary sinus were collected, and the labeled cardiomyocytes were counted in a hemocytometer. In seven individual experiments, $30 \%$ to $50 \%$ of the injected cardiomyocytes were ejected from the heart within $10 \mathrm{~min}$ of injection. These results clearly show that the direct injection of suspended cardiomyocytes carries the risk of dispersing the cardiomyocytes throughout the whole body (Hattori et al., 2010).

To improve the survival rate of cardiomyocytes, Kollosov et al. co-transfected fibroblasts with purified cardiomyocytes (Kolossov et al., 2006). In this strategy, the fibroblasts may act as bridges to facilitate the adhesion of cardiomyocytes to the myocardium and may exert a 'packing effect' to prevent the cardiomyocytes being washed out. For this approach, appropriate cell types, ideally cardiac lineages, should be used in future studies. To improve the survival rate of injected cardiomyocytes, Laflamme et al. (Laflamme et al., 2005) applied a prosurvival cocktail, which included Matrigel (a cell-permeable peptide from Bcl-XL that blocks mitochondrial death pathways), cyclosporine A (to attenuate cyclophilin D-dependent mitochondrial pathways), pinacidil (to open ATP-dependent $\mathrm{K}^{+}$channels so as to mimic ischemic preconditioning), IGF-1 (to activate Akt pathways and the caspase inhibitor ZVAD-fmk), and obtained improved survival. We encountered the same drawback, and investigated the mechanism underlying the reduced survival of injected cardiomyocytes. We studied the in vitro adhesive properties of purified cardiomyocytes and confirmed that they were less adhesive. From the above studies, it is clear that suspended cardiomyocytes are vulnerable to washing out and anoikis. To overcome these problems, we developed a "re-aggregation method", which simply means that hundreds to thousands of 
purified cardiomyocytes are aggregated in cell-non-adhesive round-bottomed 96-well plates. In this method, $>90 \%$ of the injected cardiomyocytes survive and hypertrophy in a time-dependent manner (Figure 4). The sarcomeric structures of the donor cardiomyocytes were aligned along the host myocardium. Similar experiments were successfully carried out with human ES-derived cardiomyocytes (Hattori et al., 2010). Finally, we studied the mechanism of re-aggregated cardiomyocyte or "cardiomyocyte ball" survival in vitro and in vivo. When we added several growth factors and measured the cardiomyocyte ball diameters, we identified that ET-1, EGF, bFGF, and PDGF-BB as possible autocrine/paracrine factors (Hattori et al., 2010).

\section{Myocardial cell sheets}

In 1999, the group of Okano invented the temperature-sensitive culture dish (Kaneko et al., 1999). This enabled the fabrication of cardiomyocyte cell sheets and opened up the possibility of heart regeneration using cell sheets. The Okano group demonstrated the subcutaneous transplantation of triple-layered cardiomyocyte sheets (Shimizu et al., 2006). The ectopically transplanted cell sheet could be visibly observed beating rhythmically. Subsequently, they succeeded in transplanting the cardiomyocyte sheets onto hearts (Masuda et al., 2008). However, they were unable to demonstrate a functional benefit of cardiomyocyte sheet transplantation. They commented in their papers that a triple-layered cardiomyocyte sheet is not sufficient to improve the cardiac function of damaged hearts; therefore, a multi-layered sheet with functional vasculature should be fabricated. We developed an alternative method to produce functional myocardial cell sheets using a thin scaffold composed of human fibrin and thrombin. This system has the advantage that scaffold degradation can be controlled by inhibiting internal proteinases. We also constructed triple-layered myocardial cell sheets, and performed subcutaneous and on-heart transplantations (Itabashi et al., 2005). Furthermore, we showed that an arrhythmogenic re-entry circuit caused by cryo-injury could be fixed by myocardial sheet transplantation (Furuta et al., 2006). Recently, we investigated the combination therapy of myocardial cell sheet transplantation and omentopexy, which is a surgical procedure whereby the omentum is attached to another organ for the purpose of increasing arterial circulation. This strategy synergistically ameliorated cardiac function and dilating remodeling in a long-term (8-week) study (Suzuki et al., 2009). We evaluated the mechanism underlying this synergy, and found: (1) improvement of the blood supply by OM-derived vascular and neo-vascular development in the infracted region; (2) reduction of the infracted region; (3) mechanical support of the infracted region, preventing dilation; and (4) enhancement of the long-term survival and maturation of the transplanted CM.

\section{D Tissue engineering}

Cardiac tissue engineering was first reported by Leor et al. in 2000 using an alginate porous scaffold (Leor et al., 2000). The isolated cardiac cells were seeded at a concentration of $3 \times 10^{5}$ cells per scaffold within cylindrical alginate scaffolds $(6 \mathrm{~mm}$ in diameter $\times 1.0 \mathrm{~mm}$ in height). The scaffolds has an average pore diameter of 100 $\mu \mathrm{m}$. Biograft transplantation was performed 7 days after MI. Histologic examination identified well-formed myofibers with striation, cellular gap junctions, and newly formed capillaries. Typical fibroblasts, macrophages, and lymphocytes were also found in the grafts. The beneficial effect of the biografts on LV remodeling was translated into the prevention of LV function deterioration, as reflected in the preservation of FS after implantation (53 \pm $4 \%$ versus $47 \pm 5 \%, P=0.52$ ). Over the past few years, Eschenhagen's group have developed a different technique that uses liquid collagen I instead of preformed scaffolds to reconstitute embryonic chicken or neonatal rat cardiomyocytes on three-dimensional cardiac grafts (Fink et al., 2000). The technique, which has been further proven by Zhao et al., with a minor modification, uses collagen I to support the endogenous capability of immature cardiac cells to form a heart tissue-like structure in vitro (Zhao et al., 2005). Isolated cardiomyocytes are mixed with freshly neutralized collagen type I, Matrigel, and culture medium. This cell matrix mixture is pipetted into casting molds of the desired size and shape. After 7 days in the casting molds, engineered cardiac tissues (ECTs) are transferred to a stretching device and subjected to phasic stretching by $10 \%$ for an additional 5-7 days. The contractile activity of the constructs is superb, and the method seems to be highly reproducible. Success in heart tissue repair using ECTs has been reported recently by Zimmermann et al. (2006). They derived large (1-4 $\mathrm{mm}$ in thickness $\times 15 \mathrm{~mm}$ in diameter), force-generating engineered heart tissue from neonatal rat heart cells. The engineered heart tissue formed thick cardiac muscle layers when implanted into the myocardial infarcts of immunosuppressed rats. 
When evaluated 28 days later, the engineered heart tissue showed undelayed electrical coupling to the native myocardium without evidence of arrhythmia induction. Moreover, the engineered heart tissue prevented further dilation, induced systolic wall thickening of infarcted myocardial segments, and improved the fractional area shortening of the infarcted hearts, as compared with the controls (sham-operated and noncontractile constructs). On the basis of this method, Guo et al. (2006) created cardiac tissues using cardiomyocytes derived from mouse ES cells (mESCs) (Guo et al., 2006). In that study, they enriched cardiomyocytes from mESCs using Percoll density gradients. The cells were then mixed with liquid collagen to construct cardiac tissue. The engineered cardiac tissue was mechanically stretched in vitro, and was found to resemble both structurally and functionally neonatal native cardiac muscle.

\section{Future prospective}

Mummery et al. made a long-term comparison of cardiomyocyte-transplanted and non-cardiomyocyte-transplanted samples in myocardial infarction models (Passier et al., 2008). They found that the cardiac functions of both groups were significantly improved in the short-term and long-term, as compared with the non-treated group. In the short-term, the cardiac functions of the animals treated with cardiomyocytes were significantly superior to those treated with non-cardiomyocytes; however, the long-term outcomes were not significant. Mummery et al. discussed how this might be related to an inability of the cardiomyocytes transplanted into the myocardium to work co-operatively with the host cardiomyocytes. We observed weak expression of connexin 43 protein in 2-month-transplanted mouse ES cell-derived cardiomyocytes, which was much lower than the levels in the host cardiomyocytes, suggesting that the transplanted cardiomyocytes were not fully matured. It is possible that critical points on the pathway towards full maturation of pluripotent stem cell-derived cardiomyocytes are not passed. We suspect the absence of factors that induce cardiomyocytes to mature and connect functionally with the host myocardium, i.e., humoral factors, extracellular matrixes, interactions with non-cardiomyocytes, and mechanical stress. We also postulate the existence of inhibitory mechanisms in the host heart direct against the maturation and integration into the myocardium of transplanted ES cell-derived cardiomyocytes. We further speculate that the adult myocardium has lost the ability to accept cardiomyocytes that are newly supplied during development. For the realization of the goal of "regeneration of heart using pluripotent stem cells-derived cardiomyocytes", we need to overcome these drawbacks and facilitate the process of functional integration into the host myocardium.

Tissue stem cell research has progressed in discovering intrinsic healing mechanisms and possible ways for enhancing these pathways through ex vivo stem cell expansion and the use of certain drugs. We expect that in the future these regenerative strategies will be combined with the administration of ES cell- and iPS cell-derived cardiomyocytes, which will synergistically enhance therapeutic effectiveness.

\section{References}

Anderson D, Self T, Mellor IR, Goh G, Hill SJ, Denning C. Transgenic enrichment of cardiomyocytes from human embryonic stem cells. Mol Ther 2007;15:2027-36

Asahara T. Endothelial progenitor cells for vascular medicine. Yakugaku Zasshi 2007;127:841-5

Bauwens C, Yin T, Dang S, Peerani R, Zandstra PW. Development of a perfusion fed bioreactor for embryonic stem cell-derived cardiomyocyte generation: oxygen-mediated enhancement of cardiomyocyte output. Biotechnol Bioeng 2005; 90:452-61

Beltrami AP, Barlucchi L, Torella D, Baker M, Limana F, Chimenti S, et al. Adult cardiac stem cells are multipotent and support myocardial regeneration. Cell 2003;114:763-76

Choi SC, Yoon J, Shim WJ, Ro YM, Lim DS. 5-azacytidine induces cardiac differentiation of $\mathrm{P} 19$ embryonic stem cells. Exp Mol Med 2004;36:515-23

Dow J, Simkhovich BZ, Kedes L, Kloner RA. Washout of transplanted cells from the heart: a potential new hurdle for cell transplantation therapy. Cardiovasc Res 2005;67:301-7

E LL, Zhao YS, Guo XM, Wang CY, Jiang H, Li J, et al. Enrichment of cardiomyocytes derived from mouse embryonic stem cells. J Heart Lung Transplant 2006;25: 664-74

Fijnvandraat $A C$, van Ginneken AC, Schumacher CA, Boheler KR, Lekanne Deprez RH, Christoffels VM, et al. Cardiomyocytes purified from differentiated embryonic stem cells exhibit characteristics of early chamber myocardium. J Mol Cell Cardiol 2003;35:1461-72

Fink C, Ergun S, Kralisch D, Remmers U, Weil J, Eschenhagen T. Chronic stretch of engineered heart tissue induces hypertrophy and functional improvement. Faseb J 2000;14:669-79

Furuta A, Miyoshi S, Itabashi Y, Shimizu T, Kira S, Hayakawa $\mathrm{K}$, et al. Pulsatile cardiac tissue grafts using a novel three-dimensional cell sheet manipulation technique 
functionally integrates with the host heart, in vivo. Circ Res 2006;98:705-12

Gassanov N, Er F, Zagidullin N, Hoppe UC. Endothelin induces differentiation of ANP-EGFP expressing embryonic stem cells towards a pacemaker phenotype. Faseb J 2004; 18:1710-2

Guo XM, Zhao YS, Chang HX, Wang CY, E LL, Zhang XA, et al. Creation of engineered cardiac tissue in vitro from mouse embryonic stem cells. Circulation 2006;113:2229-37

Harrison NJ, Baker D, Andrews PW. Culture adaptation of embryonic stem cells echoes germ cell malignancy. Int $\mathrm{J}$ Androl 2007;30:275-81; discussion 281

Hattan N, Kawaguchi H, Ando K, Kuwabara E, Fujita J, Murata $\mathrm{M}$, et al. Purified cardiomyocytes from bone marrow mesenchymal stem cells produce stable intracardiac grafts in mice. Cardiovasc Res 2005;65:334-44

Hattori F, Chen H, Yamashita H, Tohyama S, Satoh YS, Yuasa $S$, et al. Nongenetic method for purifying stem cell-derived cardiomyocytes. Nat Methods7:61-6

Hidaka K, Lee JK, Kim HS, Ihm CH, lio A, Ogawa M, et al. Chamber-specific differentiation of Nkx2.5-positive cardiac precursor cells from murine embryonic stem cells. Faseb J 2003;17:740-2

Hosseinkhani M, Hasegawa K, Ono K, Kawamura T, Takaya $\mathrm{T}$, Morimoto $\mathrm{T}$, et al. Trichostatin A induces myocardial differentiation of monkey ES cells. Biochem Biophys Res Commun 2007a;356:386-91

Hosseinkhani $M$, Hosseinkhani $H$, Khademhosseini $A$, Bolland F, Kobayashi H, Gonzalez SP. Bone morphogenetic protein-4 enhances cardiomyocyte differentiation of cynomolgus monkey ESCs in knockout serum replacement medium. Stem Cells 2007b;25:571-80

Itabashi $\mathrm{Y}$, Miyoshi S, Kawaguchi H, Yuasa S, Tanimoto $\mathrm{K}$, Furuta A, et al. A new method for manufacturing cardiac cell sheets using fibrin-coated dishes and its electrophysiological studies by optical mapping. Artif Organs 2005; 29:95-103

Kaneko Y, Nakamura S, Sakai K, Kikuchi A, Aoyagi T, Sakurai $\mathrm{Y}$, et al. Synthesis and swelling-deswelling kinetics of poly(N-isopropylacrylamide) hydrogels grafted with LCST modulated polymers. J Biomater Sci Polym Ed 1999;10: 1079-91

Kanno S, Kim PK, Sallam K, Lei J, Billiar TR, Shears LL. 2nd Nitric oxide facilitates cardiomyogenesis in mouse embryonic stem cells. Proc Natl Acad Sci USA 2004;101: 12277-81

Kehat I, Khimovich L, Caspi O, Gepstein A, Shofti R, Arbel $\mathrm{G}$, et al. Electromechanical integration of cardiomyocytes derived from human embryonic stem cells. Nat Biotechnol 2004;22:1282-9

Kiefer JC. Epigenetics in development. Dev Dyn 2007; 236:1144-56

Klug MG, Soonpaa MH, Koh GY, Field LJ. Genetically selected cardiomyocytes from differentiating embronic stem cells form stable intracardiac grafts. J Clin Invest 1996;98: 216-24
Kolossov E, Bostani T, Roell W, Breitbach M, Pillekamp F, Nygren JM, et al. Engraftment of engineered ES cell-derived cardiomyocytes but not BM cells restores contractile function to the infarcted myocardium. J Exp Med 2006;203:2315-27

Laflamme MA, Gold J, Xu C, Hassanipour M, Rosler E, Police $\mathrm{S}$, et al. Formation of human myocardium in the rat heart from human embryonic stem cells. Am J Pathol 2005;167:663-71

Laugwitz KL, Moretti A, Lam J, Gruber P, Chen Y, Woodard $\mathrm{S}$, et al. Postnatal isl1 + cardioblasts enter fully differentiated cardiomyocyte lineages. Nature 2005;433:647-53

Leor J, Aboulafia-Etzion S, Dar A, Shapiro L, Barbash IM, Battler $A$, et al. Bioengineered cardiac grafts: A new approach to repair the infarcted myocardium? Circulation 2000;102:III56-61

Makino S, Fukuda K, Miyoshi S, Konishi F, Kodama H, Pan $\mathrm{J}$, et al. Cardiomyocytes can be generated from marrow stromal cells in vitro. J Clin Invest 1999;103:697-705

Masuda S, Shimizu T, Yamato M, Okano T. Cell sheet engineering for heart tissue repair. Adv Drug Deliv Rev 2008; 60:277-85

Moore JC, Fu J, Chan YC, Lin D, Tran H, Tse HF, et al. Distinct cardiogenic preferences of two human embryonic stem cell (hESC) lines are imprinted in their proteomes in the pluripotent state. Biochem Biophys Res Commun 2008; 372:553-8

Muller M, Fleischmann BK, Selbert S, Ji GJ, Endl E, Middeler $\mathrm{G}$, et al. Selection of ventricular-like cardiomyocytes from ES cells in vitro. Faseb J 2000;14:2540-8

Muller-Ehmsen J, Whittaker P, Kloner RA, Dow JS, Sakoda $\mathrm{T}$, Long TI, et al. Survival and development of neonatal rat cardiomyocytes transplanted into adult myocardium. J Mol Cell Cardiol 2002;34:107-16

Oh H, Chi X, Bradfute SB, Mishina Y, Pocius J, Michael LH, et al. Cardiac muscle plasticity in adult and embryo by heart-derived progenitor cells. Ann N Y Acad Sci 2004; 1015:182-9

Pandur P, Lasche M, Eisenberg LM, Kuhl M. Wnt-11 activation of a non-canonical Wnt signalling pathway is required for cardiogenesis. Nature 2002;418:636-41

Paquin J, Danalache BA, Jankowski M, McCann SM, Gutkowska J. Oxytocin induces differentiation of P19 embryonic stem cells to cardiomyocytes. Proc Natl Acad Sci USA 2002;99:9550-5

Passier R, Oostwaard DW, Snapper J, Kloots J, Hassink RJ, Kuijk E, et al. Increased cardiomyocyte differentiation from human embryonic stem cells in serum-free cultures. Stem Cells 2005;23:772-80

Passier R, van Laake LW, Mummery CL. Stem-cell-based therapy and lessons from the heart. Nature 2008;453:322-9

Prokhorova TA, Harkness LM, Frandsen U, Ditzel N, Burns JS, Schroeder HD, et al. Teratoma Formation by Human Embryonic Stem Cells is site-dependent and enhanced by the presence of Matrigel. Stem Cells Dev 2008

Reinecke $\mathrm{H}$, Zhang M, Bartosek T, Murry CE. Survival, integration, and differentiation of cardiomyocyte grafts: a 
study in normal and injured rat hearts. Circulation 1999;100: 193-202

Roggia C, Ukena C, Bohm M, Kilter H. Hepatocyte growth factor (HGF) enhances cardiac commitment of differentiating embryonic stem cells by activating PI3 kinase. Exp Cell Res 2007;313:921-30

Rourou S, van der Ark A, van der Velden T, Kallel H. A microcarrier cell culture process for propagating rabies virus in Vero cells grown in a stirred bioreactor under fully animal component free conditions. Vaccine 2007;25:3879-89

Sauer H, Rahimi G, Hescheler J, Wartenberg M. Role of reactive oxygen species and phosphatidylinositol 3-kinase in cardiomyocyte differentiation of embryonic stem cells. FEBS Lett 2000;476:218-23

Schroeder M, Niebruegge S, Werner A, Willbold E, Burg M, Ruediger $M$, et al. Differentiation and lineage selection of mouse embryonic stem cells in a stirred bench scale bioreactor with automated process control. Biotechnol Bioeng 2005;92:920-33

Scorsin M, Marotte F, Sabri A, Le Dref O, Demirag M, Samuel $\mathrm{JL}$, et al. Can grafted cardiomyocytes colonize peri-infarct myocardial areas? Circulation 1996;94:II337-40

Shimizu T, Sekine H, Isoi Y, Yamato M, Kikuchi A, Okano T. Long-term survival and growth of pulsatile myocardial tissue grafts engineered by the layering of cardiomyocyte sheets. Tissue Eng 2006;12:499-507

Singh AM, Li FQ, Hamazaki T, Kasahara H, Takemaru K, Terada N. Chibby, an antagonist of the Wnt/beta-catenin pathway, facilitates cardiomyocyte differentiation of murine embryonic stem cells. Circulation 2007;115:617-26

Soonpaa MH, Koh GY, Klug MG, Field LJ. Formation of nascent intercalated disks between grafted fetal cardiomyocytes and host myocardium. Science 1994;264:98-101

Stary M, Pasteiner W, Summer A, Hrdina A, Eger A, Weitzer G. Parietal endoderm secreted SPARC promotes early cardiomyogenesis in vitro. Exp Cell Res 2005;310:331-43

Suzuki R, Hattori F, Itabashi Y, Yoshioka M, Yuasa S Manabe-Kawaguchi $\mathrm{H}$, et al. Omentopexy enhances graft function in myocardial cell sheet transplantation. Biochem Biophys Res Commun 2009;387:353-9
Takahashi K, Tanabe K, Ohnuki M, Narita M, Ichisaka T, Tomoda K, et al. Induction of pluripotent stem cells from adult human fibroblasts by defined factors. Cell 2007;131:861-72

Takahashi K, Yamanaka S. Induction of pluripotent stem cells from mouse embryonic and adult fibroblast cultures by defined factors. Cell 2006;126:663-76

Tomita Y, Matsumura K, Wakamatsu Y, Matsuzaki Y, Shibuya I, Kawaguchi $\mathrm{H}$, et al. Cardiac neural crest cells contribute to the dormant multipotent stem cell in the mammalian heart. J Cell Biol 2005;170:1135-46

van Laake LW, Passier R, Monshouwer-Kloots J, Verkleij AJ, Lips DJ, Freund C, et al. Human embryonic stem cell-derived cardiomyocytes survive and mature in the mouse heart and transiently improve function after myocardial infarction. Stem Cell Res 2007;1:9-24

Watanabe E, Smith DM Jr, Delcarpio JB, Sun J, Smart FW, Van Meter CH Jr, et al. Cardiomyocyte transplantation in a porcine myocardial infarction model. Cell Transplant 1998; 7:239-46

Wobus AM, Kaomei G, Shan J, Wellner MC, Rohwedel J, J $\mathrm{G}$, et al. Retinoic acid accelerates embryonic stem cell-derived cardiac differentiation and enhances development of ventricular cardiomyocytes. J Mol Cell Cardiol 1997; 29:1525-39

Yuasa S, Itabashi Y, Koshimizu U, Tanaka T, Sugimura K, Kinoshita M, et al. Transient inhibition of BMP signaling by Noggin induces cardiomyocyte differentiation of mouse embryonic stem cells. Nat Biotechnol 2005;23:607-11

Zhao YS, Wang CY, Li DX, Zhang XZ, Qiao Y, Guo XM, et al. Construction of a unidirectionally beating 3-dimensional cardiac muscle construct. J Heart Lung Transplant 2005; 24:1091-7

Zhu DY, Lou YJ. Inducible effects of icariin, icaritin, and desmethylicaritin on directional differentiation of embryonic stem cells into cardiomyocytes in vitro. Acta Pharmacol Sin 2005; 26:477-85

Zimmermann WH, Melnychenko I, Wasmeier G, Didie M, Naito $\mathrm{H}$, Nixdorff $\mathrm{U}$, et al. Engineered heart tissue grafts improve systolic and diastolic function in infarcted rat hearts. Nat Med 2006;12:452-8 